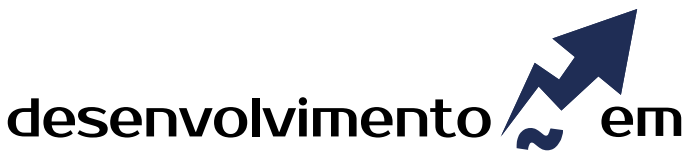 QUESTÃO
}

\section{Marketing, Tecnologia e Planejamento como Diferenciais Competitivos para Alavancar o Dark Tourism e o Desenvolvimento Local e Regional}

\author{
http://dx.doi.org/10.21527/2237-6453.2020.52.324-334
}

Recebido em: 7/11/2019

Aceito em: 19/5/2020

\author{
Vilmar Antônio Boff, ${ }^{1}$ Jonas Bordim, ${ }^{2}$ Berenice Beatriz Rossner Wbatuba, ${ }^{3}$ \\ Milton Luiz Wittmann, ${ }^{4}$ Fabiana Regina Falkembach ${ }^{5}$
}

\begin{abstract}
RESUMO
Competitividade, novas tecnologias de gestão e de informação e a alta sazonalidade e evolução de mercado, em especial no setor turístico, influíram nas estratégias de marketing tornando-as instrumentos importantes para o planejamento do desenvolvimento local e regional. Esse artigo, resultante de estudos e pesquisas desenvolvidas pelo Grupo de Pesquisas Esadi - Estudos Setoriais em Administração, Desenvolvimento e Inovação -, tem por objetivo evidenciar como um plano de Marketing pode alavancar o desenvolvimento do setor turístico, especialmente em lugares que se enquadram no conceito de Dark Tourism. Nesse sentido, trata-se de conhecer o comportamento do consumidor e obter informações necessárias para a elaboração de um plano de Marketing, de forma a impulsionar o turismo local e regional. Quanto aos aspectos metodológicos, trata-se de um referencial teórico cujos resultados identificam as vantagens de operar a gestão do turismo a partir de um planejamento que contempla a atração e a prospecção de clientes desde cinco ações estratégias: i) criação de uma marca; ii) consolidação da imagem simbólica de Sepé Tiaraju; iii) implementação do aplicativo (APP) missões; iv) criação do roteiro missões; e v) intensificação da estrutura do espetáculo som e luz. A pesquisa aponta as indicações que constam num plano de ação, cujo propósito disponibiliza um conjunto de possíveis benefícios para o desenvolvimento turístico do Sítio Arqueológico de São Miguel Arcanjo na cidade de São Miguel das Missões/RS/Brasil, inserido no contexto dos Sete Povos das Missões. Palavras-chave: Turismo. Plano de marketing. Dark Tourism.
\end{abstract}

\section{MARKETING AND TECHNOLOGY AS COMPETITIVE DIFFERENTIALS TO LEVERAGE DARK TOURISM}

\begin{abstract}
Competitiveness, new management and information technologies and high seasonality and market evolution, especially in the tourism sector, influenced marketing strategies making them an important tool for planning local and regional development. This article, resulting from studies and research developed by the Esadi Research Group - Sectorial Studies in Administration, Development and Innovation, aims to show how a Marketing plan can leverage the development of the tourism sector, especially in places that fit the concept of Dark Tourism. In this sense, it is about knowing the behavior of the consumer and obtaining information necessary for the preparation of a Marketing plan in order to boost local and regional tourism. To the methodological aspects, it is a theoretical framework whose results identify the advantages of operating tourism management based on a plan that contemplates the attraction and prospecting of clients based on five strategic actions: i) creation of a brand; ii) consolidation of the symbolic image of Sepé Tiaraju; iii) implementation of the missions application (APP); iv) Creation of the missions itinerary; and v) intensification of the structure of the sound and light show. The research points out the indications contained in an action plan, whose purpose provides a set of possible benefits for the tourist development of the Archaeological Site of São Miguel Arcanjo in the city of São Miguel das Missões/RS/Brazil inserted in the context of the Seven Peoples of the Missions.

Keywords: Tourism. Marketing-plan. Dark Tourism.
\end{abstract}

\footnotetext{
${ }^{1}$ Doutor em Desenvolvimento Regional pela Universidade de Santa Cruz do Sul (Unisc). Professor da Universidade Regional Integrada do Alto Uruguai e das Missões (URI). http://lattes.cnpq.br/6528722570008462. https://orcid.org/0000-0002-4671-627X.vaboff@gmail.com

${ }^{2}$ Mestre em Gestão Estratégica de Organizações pela Universidade Regional Integrada do Alto Uruguai e das Missões (URI). Professor da Fundação Educacional Machado de Assis (Fema). http://lattes.cnpq.br/6787953131349125. https://orcid.org/0000-0003-2988-130X. jonasbordim@hotmail.com

${ }^{3}$ Doutora em Desenvolvimento Regional pela Universidade de Santa Cruz do Sul (Unisc). Professora da Universidade Regional Integrada do Alto Uruguai e das Missões (URI). http://lattes.cnpq.br/6437353176042087. https://orcid.org/0000-0002-1496-5634. bwbatuba@san.uri.br

${ }^{4}$ Doutor em Administração pela Universidade de São Paulo (USP). Professor da Universidade Regional Integrada do Alto Uruguai e das Missões (URI). http://lattes.cnpq.br/6540542252982444. https://orcid.org/0000-0002-0305-1968. wittmann@profwittmann.com

${ }^{5}$ Mestranda em Gestão Estratégica de Organizações pela Universidade Regional Integrada do Alto Uruguai e das Missões (URI). http://lattes. cnpq.br/1807706687541561. https://orcid.org/0000-0002-1241-9699. fabianarfalkembach@aluno.santoangelo.uri.br
} 
O presente trabalho tem como tema central abordar estratégias de marketing associadas às inovações tecnológicas, visando a alavancar o desenvolvimento turístico, em especial a emergência do Dark Tourism. A delimitação deste estudo busca analisar como um plano de marketing pode potencializar o desenvolvimento do setor turístico, mais precisamente em locais que se enquadram neste conceito de turismo voltado para memórias que nos remetem a sentimentos, guerras ou mortes. Nesta senda, o artigo aborda o marketing de turismo no sentido de identificar os motivos que podem levar as pessoas a visitar estes locais, descrever o marketing aliado à tecnologia de cidades (smart cities) e apresentar as indicações estratégicas por meio de um Plano de Ação, na perspectiva de auxiliar o desenvolvimento do Dark Tourism no Sítio São Miguel Arcanjo, na cidade de São Miguel das Missões, situado na Região Noroeste do Estado do Rio Grande do Sul/Brasil.

O tema justifica-se pelo fato de que um plano de marketing turístico requer ações priorizadas, ordenadas e executadas de forma a criar condições de divulgação e aprimoramento da infraestrutura da cadeia do turismo, bem como oferecer um melhor atendimento de serviços. Igualmente, justifica-se por agregar e subsidiar novos conteúdos disponíveis a pesquisadores e operadores turísticos na área de Administração, Marketing e Turismo.

No referencial teórico são abordados vários autores, como Siqueira, Cobra, Andrade e Klaric, entre outros, e está estruturado por análise conceitual e teórica que aborda a importância do turismo; marketing de turismo; conceito de Dark Tourism, neuromarketing - psicologia e comportamento humano - e a importância de um plano de marketing para o Dark Tourism, além de abordar tecnologias voltadas a smart cities.

O presente trabalho disponibiliza resultados e estudos de pesquisas que tratam do planejamento turístico direcionados para ambientes que oportunizam o Dark Tourism como estratégia de negócios. Dentre os principais benefícios do mesmo, pode-se citar a ampliação, atração e prospeç̧ão de clientes voltados a emoções que nos levam a contextos históricos e arqueológicos, possibilitando maior visibilidade e reconhecimento do ponto turístico para atuais e futuros clientes.

\section{CONCEITUAÇÃO E IMPORTÂNCIA DO TURISMO}

Seja para conhecer novos lugares, nas férias para um descanso ou até mesmo em benefício de estudos, o turismo vem ao longo dos anos recebendo mais atenção e consequentemente importância a pessoas, organizações e governos. Alertando sobre o turismo, Cobra (2001) cita a Organização Mundial de Turismo (OMT), que estima que, no Brasil, o turismo é responsável por cerca de 5 milhões de empregos. No sentido histórico, contudo, o turismo de massa iniciou-se por volta de 1950, após a Segunda Guerra Mundial, quando muitos países depositaram no turismo suas expectativas de crescimento econômico, além de um importante fator de intercâmbio cultural entre os povos (BARRETTO, 2007).

De acordo com Siqueira (2005), a Organização Mundial do Turismo define turismo como 
[...] o deslocamento voluntário e temporário fora de sua residência habitual (superior a 24 horas, com pelo menos um pernoite e um período máximo de noventa dias), por uma razão diferente que a de exercer uma atividade remunerada. Ou seja, movimento por razões distintas de atividades de negócios ou profissionais. A ênfase é posta no aspecto recreacional (p. 78).

Ressalta-se que a importância do turismo para a economia mundial, em termos de renda, é significativa. De acordo com uma pesquisa realizada pelo Ministério do Turismo em 2008, a renda total advinda do turismo internacional foi de US\$ 1,1 trilhão, sendo responsável por cerca de $30 \%$ de todas as exportações de serviços no mundo (BRASIL, 2009). Especificamente no Rio Grande do Sul, Estado onde se deu esta pesquisa, de todos os turistas que ingressaram no Brasil no ano de 2010, aproximadamente $40 \%$ entraram pelo Rio Grande do Sul de acordo com o Plano de Desenvolvimento do Turismo do Rio Grande do Sul (RIO GRANDE DO SUL, 2012). Para Sparemberger e Zamberlan (2011):

o atual ambiente competitivo obriga as empresas a estarem permanentemente procurando novos clientes, ou seja, prospectando. Um profissional de vendas bem-sucedido precisa trabalhar na prospecção, o que envolve conseguir marcar um contato com o cliente em potencial e planejar a entrevista de vendas (p. 185).

Em relação ao turismo local, uma das atrações turísticas que recebe diariamente um grande número de turistas no Noroeste do Estado do Rio Grande do Sul, são as Reduções Jesuíticas, também conhecidas como Os Sete Povos das Missões/RS, cenário de muitas guerras e mortes envolvendo a catequização dos índios e a exploração da terra por espanhóis e portugueses, envolvendo Uruguai, Argentina e Brasil. Segundo Barbosa (2013),

visitando as Ruínas de São Miguel e de Outros Povos, os turistas admiram a extraordinária ação civilizadora dos jesuítas, que mediante a exclusiva colaboração do gentio, desenvolveram as artes, a agricultura, a pecuária e o próprio comércio exportador (p. 20).

Diante dessa afirmação, pode-se identificar que o turismo envolvendo os três países - Brasil, Uruguai e Argentina - representa um fator regional a ser estudado. Nesse sentido, a posição geográfica de países de fronteira e com os quais o Estado gaúcho faz divisa, configura-se como importante nicho para o crescimento do turismo regional.

\section{DARK TOURISM (TURISMO SOMBRIO)}

Em escala planetária, um significativo número de pessoas busca visitar pontos turísticos diferentes ou inusitados. Muitos desses lugares são memoriais, ruínas, cemitérios ou cenários nos quais ocorreram fatos históricos baseados no sofrimento ou até mesmo na morte de pessoas, a exemplo do local dos campos de concentração, do pior acidente nuclear da história ou do maior ataque terrorista da história, que são tipos de locais que ultrapassam o simples lazer, mas há acuidade humana em presenciar lembranças de épocas nestes. Neste porvir, surgiu o termo Dark Tourism (turismo sombrio), que, segundo Farmaki (2013), é conhecido como o turismo que envolve visitas a lugares reais ou recriados, que podem ser caracterizados pela ocorrência de mortes, sofrimentos, desgraças ou simplesmente algo sinistro ou macabro, que deixaram lembranças nunca esquecidas pela humanidade. 
Dark Tourism, contudo, é um tema em desenvolvimento. Segundo Pegas (2013), a partir dos anos 90 iniciou-se os primeiros estudos acadêmicos na área por meio da publicação de um editorial de Malcolm Foley e John Lennon, em 1996, para o International Journal of Heritage Studies, mas apenas no ano 2000 tornou-se um assunto mais conhecido. Apesar dos estudos recentes, a curiosidade mórbida das pessoas não é algo novo, pois, já no início do século 11, as pessoas viajavam para lugares, como Jerusalém, com o objetivo de conhecer o local da crucifixão de Jesus Cristo (ROBINSON; DALE, 2008), no entanto a nomenclatura Dark Tourism passou a ser usada só mais recentemente.

Como se pode perceber, o Dark Tourism é uma fonte de interesses de turismo voltada para aspectos emotivos, na qual fatores como o sentimento despertam a curiosidade que motiva os turistas a visitarem cenários históricos direcionados à afetividade e, quiçá, tristezas, que, em muitos momentos, nos levam para o subconsciente e inconsciente. O especialista em neuromarketing, Klaric (2012), em seus laboratórios, descobriu, através de vários estudos acadêmicos e clínicos incluindo eletroencefalogramas, que $85 \%$ do processo de decisão provém do subconsciente e do inconsciente.

Segundo Monteiro, Monteiro e Silva (2010),

seja qual for a terminologia adotada, esse segmento recente, fruto da pós- modernidade e do pós-turismo, possui relevância para a atividade que busca conhecer suas nuances e assim traçar o perfil desse público novo, suas necessidades e preferências. Identificar as características e o poder motivacional desse nicho será o diferencial para analisar o comportamento desse turista e assim conhecer medidas para seu desenvolvimento, visando ao crescimento do setor, a preservação da história e ao incremento da atividade (p. 2).

Um serviço turístico combina aspectos tangíveis e intangíveis. Os aspectos tangíveis estão caracterizados por seus atributos físicos e os aspectos intangíveis pelos benefícios buscados pelos clientes e ainda pelas emoções que o serviço possa proporcionar (COBRA, 2001). Para tentar, portanto, compreender melhor como funciona o pensamento desses clientes, procura-se sempre atrair e mantê-los, e, se possível, buscar informações na área do neuromarketing.

\section{MARKETING VOLTADO AO TURISMO E SERVIÇOS}

O marketing, mais especificamente de serviços, vem se tornando uma ferramenta fundamental para as organizações que buscam constante crescimento na captação de novos clientes. Da mesma maneira, o marketing também é importante na divulgação turística, para atrair pessoas de diversos lugares do mundo. Segundo Cobra (2001),

a medida do sucesso de uma empresa que atue no segmento de turismo e hospitalidade é que ela procura desenvolver alternativas para ampliação do valor da oferta incluindo também a relação com o cliente do cliente, ou seja, com o cliente da agência de viagens, com o cliente da operadora de turismo e assim por diante (p. 271).

O papel do setor de serviços na economia de um país abrange uma infinidade de setores da economia. O mesmo atrai segmentos de serviços, como fast-food, serviços financeiros, como bancos e investidores, companhias aéreas, serviços de telecomunicação, entre outros (COBRA, 2001), e, portanto, o marketing nesta área também se torna importante pela sua abrangência e aplicabilidade. Segundo Andrade (2012): 
o marketing de serviços é uma das áreas mais abrangentes, pois está em constante crescimento. Isso é possível de constatar se pararmos para refletir sobre quanto/ qual tipo de serviço você utiliza (e/ou estão disponíveis no seu entorno [...] os dados do IBGE apresentados no artigo Participação de Serviços, chega a 67\% em 2008 (são informações relativas ao mercado brasileiro) (p. 45).

Chiavenato (2005, p. 2) afirma que "o conceito do marketing envolve ações como vender, divulgar, propagar, promover, distribuir, definir preço, construir marca, atender ao cliente e, sobretudo, encantá-lo e fidelizá-lo". Cobra (2001), por seu turno, salienta que:

a chave em turismo é a fidelização de clientes. O comportamento do cliente bem identificado permite segmentar o mercado, agrupando clientes por estilo de vida e outros fatores demográficos e psicográficos. Oferecendo produtos e serviços de valor fica mais fácil evitar a perda de clientes. Assim a teoria da compreensão do valor percebido permite formular estratégias para manter clientes fiéis (p. 21).

Kotler (2005) afirma que "os consumidores avaliam qual oferta proporcionará maior valor. Eles procuram sempre maximizar o valor, dentro das restrições impostas pelos custos envolvidos na procura e pelas limitações de conhecimento, mobilidade e renda" (p. 40). Em tratando-se de um lugar em específico e não de um produto, fica mais difícil ainda realizar essa compreensão do que o cliente espera encontrar ao realizar o turismo. Segundo Cobra (2001), "como o produto turístico é uma combinação de ação e emoção em que os aspectos tangíveis e intangíveis se sobrepõem numa mistura entre o real e o imaginário, a criatividade do setor deve ser intensa" (p. 36).

Nesta senda, Kotler e Keller (2006) ressaltam que "fazer marketing significa satisfazer as necessidades e os desejos dos clientes. O dever de qualquer negócio é fornecer valor ao cliente mediante lucro" (p. 34), entretanto a escolha de como procurar clientes pode ser feita de muitas formas e varia de acordo com o objetivo traçado. Atualmente o modelo mais utilizado é a internet por meio de sites de busca ou relacionados com viagens. Segundo Cobra, "com o impacto dos sistemas informatizados, como a internet, o setor de turismo necessita reavaliar o seu papel na criação e na administração da demanda de serviços de viagem, lazer e hospitalidade" (2001, p. 36), mas, também, pode ser realizado mediante indicações de pessoas que já visitaram o local, chamado de marketing boca a boca, além da divulgação em feiras, catálogos, fôlderes, anúncios, agências de viagens e outros meios de comunicação.

\section{COMPORTAMENTO HUMANO EM RELAÇÃO AO TURISMO}

Um dos motivos que torna este estudo interessante, do ponto de vista acadêmico como também de mercado, é saber quais são os motivos que levam as pessoas a sentirem-se atraídas por lugares mórbidos ou de características sinistras. Uma das explicações pode ser encontrada no conceito de neuromarketing, que, segundo Camargo (2009), "trata de pesquisas de comportamento do consumidor, isto é, do estudo de como o anúncio realmente influencia as pessoas e até que ponto o faz" (p. 75).

Outra razão é encontrada no ramo filosófico, mais precisamente na palavra de origem alemã, Schadenfreude, que, conforme Leite (2007), significa a alegria ou o prazer que as pessoas têm com o sofrimento alheio. Baptista e Coutinho (2013) realçam que 
pessoas com condições de viajar são atraídas por diferentes motivações, posto que estas podem estar relacionadas a locais com diversas atrações, entre elas relações com a morte, sofrimento, violência ou até catástrofes, a exemplo das Torres Gêmeas de Nova York. Para Cobra, "a escolha no processo de compra de turismo e viagens é também influenciada por quatro fatores psicológicos: motivação, percepção, aprendizado, crenças e atitudes" (2001, p. 148). Aprofundando ainda mais sobre o assunto, Viscott (1982) afirma que:

[...] filme de aventuras nos segura e nos mantém nas poltronas à medida que nos identificamos com pessoas fictícias ameaçadas por criaturas poderosas, aparentemente invencíveis, espíritos, holocaustos, terremotos, tubarões. O envolvimento que estas aventuras suscitam reflete nosso instinto básico de sobrevivência. $O$ sentimento de assumir um risco básico de sobreviver é revigorador: dá um novo sentido à vida. Seguramente esta é a razão pela qual os esportes que implicam risco são tão excitantes (p. 48-49).

Estudos revelam que atrações muito antigas também vêm ao encontro do conceito do Dark Tourism. Um exemplo a ser citado são os jogos que eram realizados por gladiadores no antigo Coliseu de Roma na Itália, quando a morte de um competidor era comemorada por uma grande plateia (STONE, 2006). Vale lembrar, também, que, na época, a maioria das execuções era realizada em locais públicos como forma de castigo para a pessoa punida, e de espetáculo para o público. Em razão dessa série de fatores, torna-se importante a avaliação do neuromarketing, que, segundo Klaric (2012), é um estudo que une primeiramente a antropologia, seguida pelos profissionais de psicologia e, depois, entrando na área da neurologia, não se detendo apenas às ciências sociais e aplicadas.

Percebe-se que, dentro do ramo turístico, o segmento sombrio e mórbido de lugares, aqui identificados como Dark Tourism, aponta uma enorme possibilidade de atrair grande quantidades de visitantes sedentos por histórias ou curiosidades que nos levam a sentimentos e emoções de realidades sombrias passadas. Este é o caso do sítio arqueológico de São Miguel das Missões, que retrata histórias sombrias e emotivas relativas a guerras e à dizimação de índios.

\section{PLANO DE MARKETING PARA O DARK TOURISM}

O Dark Tourismo é uma área que apresenta crescimento expressivo no mercado por trabalhar, entre outros fatores, com a curiosidade, sentimentos, memórias e emoções das pessoas. Esse crescimento expressivo no mercado, porém, pode não se concretizar se a empresa privada, governo ou investidores responsáveis pelo lugar, enquadrados no conceito de Dark Tourism, associarem-se à ausência de um planejamento. Depois de conhecer o lugar em que se enquadra o conceito de Dark Tourism, torna-se importante estudar sua história, sua cultura e o pensamento das pessoas a respeito do mesmo; desta forma, tem-se os elementos necessários para desenvolver um plano de marketing para alavancar o turismo local e regional.

De acordo com o Ministério do Turismo, é grande o desafio de construir um plano de marketing capaz de atender às necessidades de promover um país, aproveitando as oportunidades advindas de eventos e, ao mesmo tempo, dar apoio à comercialização dos produtos, serviços e destinos turísticos (BRASIL, 2009). De acordo com Kotler e Kotler (2015): 
o desenvolvimento e o detalhamento do plano de marketing são imprescindíveis. Porém, faz mais sentido chamá-lo de plano de batalha. O plano deve oferecer razoável probabilidade de que se ganhará a guerra antes da primeira batalha. Caso não esteja produzindo algo melhor, mais novo, mais rápido ou mais barato, é meIhor não entrar no mercado (p. 174).

Para a elaboração de um planejamento, contudo, sugere-se a utilização da ferramenta 5W2H. Para Stadler (2008), "a ferramenta 5W2H, é uma técnica que define uma ação para todas as etapas de análise e de melhoria de processos. $5 \mathrm{~W}+2 \mathrm{H}$ são perguntas que têm o objetivo de instigar respostas aos problemas a serem resolvidos e/ou organizar ideias na resolução de problemas" (p. 10).

Percebe-se que, diante de todos os referenciais pesquisados, um adequado plano de marketing, necessariamente, precisa contemplar: a ampliação de mercado, a atração e a prospecção de clientes que proporcionarão maior retorno financeiro, a visibilidade e o reconhecimento do ponto turístico para atuais e futuros clientes. O Plano de Ação contempla ações que visam a melhorar a experiência do visitante, ao mesmo tempo em que potencializa o turismo, a exemplo de ações que potencializam o Sítio Arqueológico São Miguel Arcanjo na região das Missões no Estado do Rio Grande do Sul. Desse modo, propõe-se uma maneira inovadora como forma de divulgar o produto turístico do Sítio Arqueológico São Miguel Arcanjo, por meio de cinco ações: i) criação de uma marca; ii) consolidação da imagem simbólica de Sepé Tiaraju; iii) instalação do aplicativo (APP) missões; iv) Criação do roteiro missões; e v) intensificação da estrutura do Espetáculo Som e Luz. Além da descrição de cada produto, também está disponível um Plano de Ação individual com base no método 5W2H. Segundo Peinado e Graeml (2007), o $5 \mathrm{~W} 2 \mathrm{H}$ tem como objetivo reduzir a ocorrência de dúvidas em relação a uma ação por intermédio das seguintes perguntas:

- WHAT? (O quê?) - Qual tarefa? O que será feito?

- WHERE? (Onde?) - Onde será executada a tarefa?

- WHY? (Por quê?) - Por que esta tarefa é necessária?

- WHO? (Quem?) - Quem vai fazer?

- WHEN? (Quando?) - Quando será feito?

- HOW? (Como?) -De que maneira será feito?

- HOW MUCH? (Quanto?) - Quanto custará?

\section{SMART CITIES COMO FERRAMENTA DE APOIO AO DESENVOLVIMENTO TURÍSTICO}

Este tópico apresenta conceitos relacionados ao tema de cidades inteligentes (smart cities). Este tema tem se acentuado em razão de as pessoas passarem a conviver em grandes centros urbanos e necessitarem encontrar alternativas de sustentabilidade ambiental e social de melhor convivência em cidades no contexto econômico global, com melhorias na qualidade de vida.

Nam e Pardo (2011) relatam que as cidades têm crescido rapidamente e que esse crescimento populacional na zona urbana carece de adequação de planejamento, em especial na estrutura de transporte, melhorias de estradas, diminuição da poluição e di- 
minuição de riscos, os quais podem ser exemplos de melhorias sociais. Nesse sentido, as Tecnologias da Informação e Comunicação (TICs) são fundamentais para a estruturação das Cidades Inteligentes, efetivando melhorias no cotidiano das pessoas inseridas no contexto, seja em sua vida pessoal ou profissional, incrementando aspectos inovadores e colaborativos nas cidades (KOMNINOS; SEFERTZI, 2009).

Segundo Webber e Wallace (2009), as chamadas Cidades Inteligentes englobam tecnologias que promovem melhorias significativas em diferentes ramos de atividades, por exemplo: eficiência energética; otimização de produção; sistemas de monitoramento e gestão; infraestrutura; colaboração mútua, saúde e educação aliada à internet; e melhoria logística por meio de etiquetas digitais para rastreamento de mercadorias e objetos, que, além de facilitar o controle e gestão dos meios urbanos, estimulam melhorias sociais e ambientais à sociedade, surgindo uma nova área para auxiliar no método tradicional de como também pode ser explorado o turismo no contexto atual: o turismo inteligente.

\section{Turismo inteligente}

Uma das áreas que pode ser beneficiada com as smarts cities é a do turismo. 0 turismo inteligente é um método de conseguir vantagens competitivas, fazendo com que os benefícios do setor turístico impactem em outros áreas, potencializando, dessa maneira, a economia local (MUÑOZ; SÁNCHEZ, 2013).

Para Jiang (2013), o uso da tecnologia, aliada ao turismo, é uma forma de inovar a maneira de gestão, aumentando a competividade com o alinhamento dos serviços prestados, potencializando os recursos físicos e o uso das informações disponíveis para melhorias locais e regionais com relação ao turismo, ou seja, a interação entre informação e comunicação torna-se aliada do turismo, graças à tecnologia que vem transformando as experiências turísticas cada vez mais inesquecíveis. Conforme Neuhofer e Buhalis (2013),

a gama de tecnologias de informação e comunicação que acompanham o turista munido de qualquer dispositivo, em qualquer lugar e a qualquer hora, está maximizando as possibilidades de introduzir novas formas de criar experiências de tecnologia melhorada em todos os lugares ao longo da viagem do consumidor, por exemplo, pré/durante/pós viagem (p. 2).

Na prática, as principais fontes de informações que acabam gerando conteúdo por parte dos turistas, podem ser por redes sociais, sites de compartilhamento, sites de avaliação do consumidor, imagens, fotografias e marketing "boca a boca" (seja presencial ou por meio da internet) (MUÑOZ, 2013). Em relação à melhoria da gestão do ponto turístico, o autor complementa que os destinos turísticos inteligentes estão ligados ao aumento da competitividade e nível de experiência turística e, segundo Muñoz e Sánchez (2013), também do espaço inovador, o qual realça as vantagens advindas de inovações tecnológicas aplicadas ao turismo.

\section{Tecnologia aliada ao marketing de turismo}

Do ponto de vista tecnológico, tem-se que um ponto turístico inteligente, com o auxílio da velocidade das informações via internet, aumenta sua visibilidade e também a quantidade de pessoas que visitam o local. Para que isso seja possível, porém, são ne- 
cessárias algumas alterações no processo de gestão do turismo, a exemplo da existência de um plano de marketing que possibilita aos operadores de gestão tomar decisões de forma otimizada, orientada e guiada por um passo a passo.

No campo da gestão empresarial, a orientação precisa, a visão de demanda e a estratégia, requerem planos com base em ações nas quais o desenvolvimento e o detalhamento do plano de marketing são imprescindíveis, porém faz mais sentido chamá-lo de plano de batalha. O plano deve oferecer razoável probabilidade de que se ganhará a guerra antes mesmo da primeira batalha, pois, caso não se esteja introduzindo algo melhor, mais novo, mais rápido ou mais barato, é melhor não entrar na guerra de mercado (KOTLER; KOTLER, 2015, p. 174).

Após formulada as ações a serem desenvolvidas, Rosa (2007) afirma que é preciso determinar formas de como você irá divulgar seus produtos, pois estas implicam custos. $\mathrm{O}$ autor sugere o uso da criatividade para encontrar as melhores maneiras de divulgar seus produtos ou, então, observar seus concorrentes para fazer melhor. Como começar, porém, na prática, as ideias que o turismo inteligente visa a melhorar? Essas respostas podem ser construídas juntamente com o próprio visitante do local. Segundo Buhalis e Foerste (2015), o marketing pode trabalhar com a cocriação de valor, ou seja, a criação de valor em parceria com todos os envolvidos, sejam eles comunidade, usuários, gestores públicos e privados, de todas as partes interessadas que podem vir a utilizar informações. Após a coleta das informações, mediante uma série de sensores, o destino turístico Inteligente pode disponibilizar, em tempo real, uma gama de informações que influencia no planejamento, na gestão e no aumento da experiência turística.

Uma ideia aliada às Smart Cities proposta para esses locais, é a criação de um aplicativo para smartphone (APP). Esse aplicativo teria uma plataforma em que os turistas poderiam acessar fotos, vídeos, expor seus elogios, suas críticas e demais informações ligadas ao local visitado estando, o mesmo, para download na página oficial do ponto turístico de maneira gratuita. Por meio de tecnologias de informação e comunicação que acompanhariam o turista que tiver o aplicativo em seu dispositivo, em qualquer lugar e a qualquer hora ele aumentaria a proximidade e o relacionamento ao longo da viagem. Tudo isso antes, durante e depois da visita (NEUHOFER; BUHALIS, 2013).

Depois do desenvolvimento da estratégia, a empresa deve elaborar programas detalhados de apoio, pois a melhor ação de marketing pode ser arruinada se inadequada. Para isso, as organizações não devem se deter apenas a um determinado público, e sim direcionar suas ações para todos os seus stakeholders - clientes, funcionários e fornecedores. A empresa pode ter como objetivo entregar níveis de satisfação acima do mínimo a diferentes públicos (PORTELA, 2012).

Para os responsáveis pelo ponto turístico, seja o setor público ou privado, esse aplicativo será importante, pois pode auxiliar na gestão do mesmo, ampliando a divulgação, interagindo com pessoas do mundo inteiro por intermédio da internet, e, ainda, melhorando aspectos negativos que podem aparecer nos comentários. 


\section{CONSIDERAÇÕES FINAIS}

Atualmente as empresas pensam cada vez mais em novas ações de marketing e estratégias com um objetivo principal de manter e prospectar clientes. Para isso, torna-se importante o planejamento de ações inovadoras para continuar mostrando seu trabalho em busca de novas estratégias e inovações.

Nesse artigo, foram descritos importantes benefícios a serem considerados ante a elaboração de um plano de marketing no setor turístico, mais precisamente em lugares enquadrados no conceito de Dark Tourism, com o intuito de ampliação de mercado e, ao mesmo tempo, aplicando um marketing para atrair e satisfazer potenciais clientes. $\mathrm{O}$ objetivo central foi evidenciar o planejamento de marketing para o turismo por meio da disponibilização de estratégias identificadas e estruturadas em um plano de ação para o Sítio São Miguel Arcanjo, no município de São Miguel das Missões.

Inicialmente abordou-se sobre o que é o turismo e sua importância no contexto do desenvolvimento Local e Regional. Em seguida, descreveu-se como funciona o marketing de turismo e os aspectos relacionados à sua ampla e irrestrita divulgação e abrangência. Também se abordou os motivos que levam as pessoas a visitar tais pontos turístico relacionados à temática de Dark Tourism, de forma a conhecer detalhes de como essa modalidade de turismo pode ser analisada pela via psicológica e de comportamento humano.

Não menos relevante, tecnologias de informação potencializam a ligação e a compreensão dos espaços turísticos no momento da visitação, a qual fez parte das ações estratégicas do Plano de Ação executado na pesquisa que originou este trabalho. Propõe-se uma maneira diferente de divulgar o produto turístico do Sítio Arqueológico São Miguel Arcanjo, mediante a elaboração de cinco ações: i) criação de uma marca; ii) consolidação da imagem simbólica de Sepé Tiaraju; iii) instalação do aplicativo (APP) missões; iv) criação do roteiro missões; e v) intensificação da estrutura do Espetáculo Som e Luz. Por fim, destaca-se que um plano de marketing, aliado à tecnologias de informação, potencializa o desenvolvimento do Dark Tourism por meio da promoção do espaço de visitação e atrações num ambiente próspero e inovador. Assim, são vários os benefícios que um eficiente e eficaz planejamento pode acrescentar ao setor, entre eles: ampliação de mercado, atração e prospecção de clientes, maior visibilidade e reconhecimento do ponto turístico para atuais e futuros clientes.

\section{REFERÊNCIAS}

ANDRADE, Carlos Frederico de. Marketing: o que é? quem faz? quais as tendências? Curitiba: InterSaberes, 2012.

BAPTISTA, Maria Manuel; COUTINHO, Belmira. O turismo negro como experiência de ócio humanista aproximações entre conceitos aparentemente distantes. 2013. Disponível em: www.mariamanuelbaptista.com/pdf/15_Ocio_Belmira_Português.pdf. Acesso em: 10 out. 2015.

BARBOSA, Fideles Dalcin. História do Rio Grande do Sul. Passo Fundo: Projeto Passo Fundo, 2013.

BARRETTO, Margarita. Cultura e turismo: discussões contemporâneas. Campinas: Papirus, 2007.

BRASIL. Plano aquarela 2020: marketing turístico internacional do Brasil. Brasília: Ministério do Turismo, 2009.

BUHALIS, D.; FOERSTE, M. SoCoMo marketing for travel and tourism: empowering co-creation of value. Journal of Destination Marketing and Management, 4, p. 151-161, 2015 Disponível em: http://daneshyari.com/article/preview/1011039.pdf.

CAMARGO, Pedro. Neuromarketing: descodificando a mente do consumidor. Porto: Ipam, 2009. 
CHIAVENATO, Idalberto. Administração de vendas: uma abordagem introdutória. Rio de Janeiro: Elsevier, 2005.

COBRA. Marketing de serviços: turismo, lazer e negócios. 2. ed. São Paulo: Cobra, 2001.

FARMAKI, A. Dark tourism revisited: A supply/demand conceptualisation. International Journal of Culture, Tourism and Hospitality, 7(3), p. 281-292, 2013.

ROBINSON, N.; DALE, C. Can I get a witness? An examination into the role of dark tourism to aid investigations into unsolved cold case muder files. The Dark Tourism Fórum. Disponível em: http:// www. dark-tourismforum/the dark tourism article.mht Acesso em: 30 mar. 2020.

KLARIC, Jürgen. Estamos cegos. São Paulo: Planeta, 2012.

KOMNINOS, N.; SEFERTZI, E. Intelligent cities: R\&D offshoring, Web 2.0 product development and globalization of innovation systems. In: Proceedings of the Second Knowledge Cities Summit, 2009.

KOTLER, Philip. Marketing essencial: conceitos, estratégias e casos. 2. ed. São Paulo: Prentice Hall, 2005.

KOTLER, Philip; KOTLER, Milton. Marketing de A a Z e marketing de crescimento: Edição 2 em 1 . Rio de Janeiro: Elsevier, 2015.

KOTLER, Philip; KELLER, Kevin Lane. Administração de marketing. 12. ed. São Paulo: Pearson Prentice Hall, 2006.

JIANG, H. The research review of intelligent tourism. Journal of Management and Strategy, 4(4) 65-67, 2013. Disponível em: www.sciedu.ca/journal/index.php/jms/article/viewFile/3631/2144.

LEITE, Dante Moreira. O caráter nacional brasileiro: história de uma ideologia. 7. ed. São Paulo: Editora Unesp, 2007.

MONTEIRO, Jaqueline de Oliveira; MONTEIRO, Jéssica de Oliveira; SILVA, Erly Maria de Carvalho. Turismo macabro: conhecer para entender; entender para (des)construir. 2010. Disponível em: http://www.anptur.org.br/ocs/index.php/seminario/2010/paper/downloadSuppFile/839/401. Acesso em: 10 set. 2017.

MUÑOZ, Ávila. L. Creating a smart destination. 2013. Disponível em: www.morocco-forum.com/downloads/presentations/Antonio-lopez-de-Avila-Munoz-Creating-a-Smart-Destination.pdf.

MUÑOZ, A. L.; Á, SÁNCHEZ, S. G. Destino turístico inteligente. Harvard Deusto Business Review, 224, p. 5867. 2013. Disponível em: http://www.harvard-deusto.com.

NAM, T.; PARDO, T. A. Conceptualizing smart city with dimensions of technology, people, and institutions. The Proceedings of the 12th Annual International Conference on Digital Government Research. 2011. Disponível em http://inta-aivn.org/images/cc/Urbanism/background\%20documents/dgo_2011_smartcity.pdf.

NEUHOFER, B.; BUHALIS, D. Tecnology enhanced tourism experiences. Digital Tourism Think Tank, p. 2-13, 2013.

PEGAS, Ana Paula Martins Castro. O visível que não se vê e o património cemiterial: proposta de criação de uma Rota Turística dos Cemitérios do Porto. 2013. Disponível em: http://sigarra.up.pt/flup/pt/publs_ pesquisa.show_publ_file?pct_gdoc_id=81032. Acesso em: 10 out. 2015.

PEINADO, Jurandir; GRAEML, Alexandre Reis. Administração da Produção - Operações Industriais e de Serviços. Curitiba: Unicen P, 2007.

PORTELA, C. B. M. O marketing e o comportamento do consumidor. 2012. Disponível em: http://www. convibra.com.br/upload/paper/adm/adm_3488.pdf.

RIO GRANDE DO SUL, Secretaria de Turismo do Estado do Rio Grande do Sul. Plano de desenvolvimento do turismo do Rio Grande do Sul: 2012-2015. Rio de Janeiro, 2012.

ROSA, Cláudio Afrânio. Como elaborar um plano de negócio. Brasília: Sebrae, 2007.

SIQUEIRA, Deis. História social do turismo. Rio de Janeiro: Garamond; Brasília: Ed. Vieira, 2005.

SPAREMBERGER, Ariosto; ZAMBERLAN, Luciano. Vendas: fundamentos e relacionamento com clientes. 1 ed. Ijuí: Editora Unijuí, 2011.

STADLER, H. Sistemas de avaliação e qualidade. Curitiba: Fotolaser, 2008.

STONE, Philip R. A dark tourism spectrum: towards a typology of death and macabre relates tourist sites, attractions and exhibitions. Tourism, v. 54, n. 2, p. 145-160, 2006.

VISCOTT, David. A linguagem dos sentimentos. São Paulo: Ed. Summus, 1982.

WEBBER, L.; WALLACE, M. Green tech: how to plan and implement sustainable IT solutions. New York: Amacon, 2009. 